EDUCATION FOR THE MENTALLY HANDICAPPED IN DENMARK

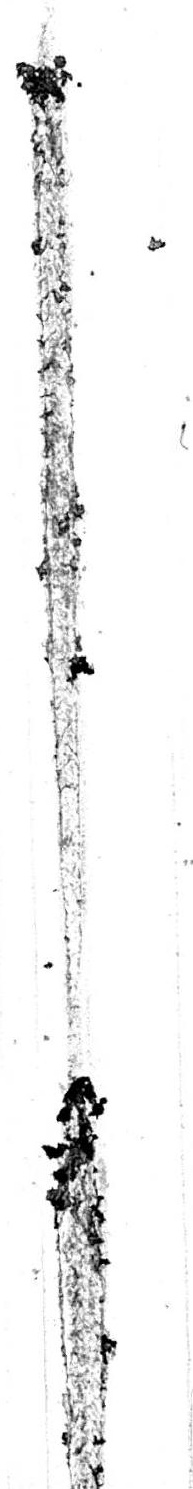

\section{PERSPECTIVES ON EDUCATING THE MENTALLY HANDICAPPED IN DENMARK}

\section{By J. Liebe-Lindgreen, Halvor Egkvist, and Henning Sletved ${ }^{1}$ Translated by Vibeke Bloch}

The pupils referred to schools for the mentally handicapped are a motley crowd with various difficulties in learning, but their main problem is their poor ability to manage new situations by means of former experience and on the basis of their imagination and acquired concepts.

The education in the schools for mentally handicapped pupils must consequently be considered as a treatment having two main goals: the development of the capacities and abilities of the pupils, strengthening their character; and the impartment of useful knowledge, so that each of them can attain the greatest possible achievement in private life and in the community according to his abilities. The second goal requires a constant analysis of the areas of society where pupils are likely to find suitable work.

\section{THE PUPILS}

The pupils referred to schools for the mentally handicapped are not essentially different from pupils of the primary schools.

They are referred to special education because their intellectual retardation is so great that the primary schools have no possibility of giving them an adequate education and the amount of knowledge necessary in our culture. Two chief reasons for this. are the lack of specially trained teachers and inadequate buildings. The decentralized administration of the primary schools further makes it difficult to give necessary service to pupils with great handicaps. But even more important is the regard for the handicapped pupils themselves, who in a special school have the possibility of seeing themselves as members of the primary group, perhaps for the only time in their lives.

Intellectual retardation manifests itself as special difficulties in understanding and in learning skills, and a pupil is referred to special education either for these reasons alone or when they appear combined with other difficulties, such as behavior disorders. Thus admission to school for the mentally handicapped is not only dependent on the result of an intelligence test, expressed as a quotient, but is always based on a total impression of the pupil's responsiveness to education. The total evaluation is also based on psychological and social elements.

1. J. Liebe-Lindgreen is Principal of a school for the mildly retarded in Denmark. Halvor Egekvist is Chief Educational Offier, Forsorgscentret for Fyn, Nyborg, Denmark. Henning Sletved is Inspector of Education, The Danish National Service for the Mentally Retarded. Vibeke Bloch is Headteacher of Stensagerskoken in Stensagervej, Denmark.

(C) Love Publishing Company 1970 
It follows that pupils in a school for mentally retarded children differ widely. In a class for mentally retarded children there is generally very great diversity as to physique, intelligence, behavior, and sensibility, and the impairment of each pupil varies from one ability to another.

\section{BACKGROUND OF THE PUPILS}

It has been said that the pupils in schools for the mentally retarded do not differ essentially from pupils in primary schools-ordinary children-but they are set apart by their mental retardation, and in connection with their low intelligence there are a considerable number of neurological problems in the form of further handicaps. It must be stressed that the difficulties arise not only from the degree of retardation but also from the quality of the retardation of each pupil. Normally we distinguish between pathological cases and subcultural ones (negative variants). In literature we find varying percentages for the relative numbers of these two groups. For the present, however, only two conditions are of importance: first, that we realize this difference when we plan our education with consideration to our aim and our means; and secondly that we make sure of special medical assistance. These conditions are all-important in determining thè content, planning, and execution of our teaching. Apart from the intellectual retardation of our pupils, their difficulties will appear as defective concentration: they are easily diverted, they get tired very soon, and their feelings are easily excited. Consequently they take a longer time to learn, they remain on the same level for a longer time than usual, and their capacity for learning is very restricted.

It will be understood that we cannot treat all pupils in the same way, and what is allowed for one pupil is not necessarily allowed for all the others. The sense of jus-

FOCUS ON EXCEPTIONAL CHILDREN is published monthly except June, July, and August as a service to those concerned with mentally retarded and emotionally disturbed children. Subscriptions rates, $\$ 9.50$ per year. Copyright 1970 Love Publishing Company. All rights reserved. Reproduction in whole or part without written permission is prohibited. Printed in the United States of America. Second class postage is paid at Denver, Colorado.

Executive and Editorial Offices

6635 East Villanova Place

Denver, Colorado 80222

Telephone (303) 757-2579

\section{EDITOR}

Dr. Edward L. Meyen The University of Iowa

Washington Report

Valeita J, Naegle

Stanley F. Love

Publisher tice of the teachers must always be considered in relation to each pupil and each situation.

Before we can plan any education we must understand each pupil as thoroughly as possible, and he must be tested with regard to intelligence and character, because it is.necessary for the teacher to have all relevant information.

Before the actual teaching is started the teacher must be in possession of a thorough description of each pupil. On the basis of this description and his own evaluation of the pupils he can plan the influence to which he wants the pupils submitted, pedagogically and psychologically.

Maturity rather than acquired skills must determine the time for each step of the treatment. It is important that teaching is not started too early because of irrelevant considerations.

For instance, teaching should not be started on account of mechanical skills in reading or arithmetic, but only when the pupil has reached sufficient maturity. The problem is, however, very complicated, because maturity is not only the result of natural development but is acquired through the influence of the surroundings. In schools with kindergartens or occupational departments it is recommended to start teaching gradually, beginning for instance with one lesson a day and augmenting the number of lessons only whep the pupils are ripe for it.

\section{SUBJECT MATTER OF THE TEACHING}

The subjects are chosen with regard to the aim of the education and the possibilities of the pupils. We must mention, however, the difficulties arising from the discrepancy between the age and interests of the pupils on the one side and their retarded intellectual development on the other side. This discrepancy makes it impossible to plan a teaching with equal regard to both conditions. In order to motivate the pupils, especially the older ones, "it is often necessary to start with subject matter which does not seem in accordance with the intellectual possibilities of the pupils.

Consequently we have not always given a list of subjects with rising difficulties, for instance as to general information and sex instruction; and in other subjects, such as arithmetic and camp-school, we have made several suggestions of equal difficulty. Another difficulty is caused by the fact that many of our pupils are unable to form a structure of ideas and concepts based on their own experience. Consequently it is important in all teaching to stress concept formation; perhaps it is the most important element in all our teaching.

In order to achieve this important goal it is not enough to create language-stimulating situations in class; the 
teacher must realize exactly the level of each pupil and plan hi further development. The importance of this work is further stressed by many investigations which seem to prove that lack of concepts are more fatal to later success than the lack of other skills. However, further investigations in this field are greatly needed.

In this connection we mention language stimulation, as the spoken language for many of our mentally retarded pupils will be the only means of communication with their surroundings, and a good language is also a necessity for concept formation.

With regard to the teaching of each subject it must be stressed that a subject is not a goal in itself but must be considered as a means to the general aim of education as mentigned above. Special skills in various subjects will only be useful if they are part of a comprehensive totality. Consequently it is necessary to connect the subjects with each other in such a way that they supply a general outlook on the events of everyday life.

\section{THE FORM OF THE INSTRUCTION}

It has been mentioned that the difference between mentally handicapped pupils and the pupils of primary schools must be sought in the degree and the number of retarding elements. Modern psychology tells us that both grops of pupils are submitted to the same psychologich laws. Further investigations are necessary before $\mathrm{n}$ can be regarded as an absolute fact. But for the time being we must plan the form of our teaching with dul regard to this assertion.

\section{METHO OF THE TEACHER}

When a teacher within his field of activity has determine his aim and the possibilities of the pupils, he must chi se his subject matter (the content of the teaching). Or this basis he must plan the form of the teaching (method, which will be manifested in the teaching itself (piactice). Both the choice of the subject matter and the planning of each lesson must be carried out on these lines.

With regard to the choice of methods, the teaching must be planned with equal regard to individual instruction on one hand and group work on the other (i.e. tasks that can solved by a common effort only). This is importaffor the social development of the pupils and teache 1 collaboration and acceptance. The groups need nithlyays consist of the same pupils; on the contrary, it dimportant now and then to give the pupils an opportul $y$ to work under new conditions and among new frik ds. The "green schools," modern schools in rural 'sul undings, will provide excellent conditions for this sort of work.

Collective teaching as it used to be practiced must not take up too much time, especially with the younger children. With the older pupils this method can have some value, for instance as a means to teach the pupil that he is not always the center of the classroom and that he cannot always be dependent on the teacher, and of course it is the only method in a subject such as physical training and to a certain extent, social studies.

Concerning the understanding of the subject matter, it must be realized that the previous knowledge and the possibilities of the pupils vary widely, not only as to perception but even more as to conception.

The teacher must plan his instruction with due regard to the possibilities of perception of each pupil. The teaching must primarily appeal to the best developed perception. Many pupils have perception disorders caused by complicating handicaps. These disorders are often extremely resistant to treatment, and the treatment must be planned in connection with teachers who have a special education in the field in question. It is often impossible to decide which handicap must be treated first or most intensively; consequently it is important for the teaching not to be too one-sided.

It is necessary for the teacher to evaluate the achievements of the pupils. In this connection it is important to distinguish between:

a. Control (by the teacher-by the pupil)

b. Evaluation of the achievements

c. Reward of the pupil

\section{CONTROL}

No teacher, however efficient he may be, can work appropriately without controlling his results now and then. The more concrete and differentiated this control is, the easier it is to change the line of work if necessary. This must be considered a working order and not an evaluation of results, a distinction which is often forgotten by teachers who do not like control. It is difficult to give exact rules as to how often the achievements of the pupils should be estimated; however, it is usually not done often enough. If a thorough evaluation is carried out only once a year there are too few possibilities for correction. Some schools give an evaluation of all pupils once a term, others once a month, and they find the work rewarding.

Such an evaluation is often difficult because we have no standard of comparison and no unambigious language to express our evaluation. We are trying to supply these aids; until then the teacher will manage fairly well if he is aware of the difficulties. 


\section{EVALUATION OF THE ACHIEVEMENTS}

The evaluation of the achievements of a pupil compared with his former achievements and possibly compared with those of his friends can be expressed in a fairly objective way and will say something of the knowledge of a pupil at a certain time. Apart from this it is possible to evaluate diligence and behavior, but it is important not to mix these three things.

\section{REWARD OF THE PUPIL}

As we shall see in the next paragraph, it is important for the pupil to feel success in his work. This does not mean that the teacher must praise all achievements, but he must find a suitable balance between the possibilities of the pupils and the praise and blame administered in such a way that the pupils find motivation to continue their work. It is important to discuss the achievement, and not the pupil. In this way both pupil and teacher will feel free, and the teacher will be able to use his reward as a mental stimulation for the pupil.

The attitude of the teacher is important for the relation between teacher and pupil. He must be positive, yet not sentimental; realistic, but not deprecating.

\section{METHODS OF THE PUPIL}

In the schools for mentally retarded children the aim is to further the personal development of each pupil rather than to give a certain number of pupils a certain amount of knowledge. Consequently individual instruction will take up a great part of the school time; this is in accordance with the need for developing the abilities and potential of the pupils and to give them useful knowledge. Character training will not be met within this form of instruction, as the pupil is mainly exposed to the influence of the teacher and has no interplay with the group.

Motivation is the impulse of the pupil to receive instruction. It takes its origin from the subject matter, from the teacher's form of instruction, and from the methods. This necessitates that all teaching take its starting point from things that are concrete and vital to the pupils. The pupils are further motivated from experience and comprehension. Consequently all training of skills must follow the principle of learning through application (functional teaching), and not the principle of training details, the use of which are not evident to the pupils (formal teaching). If formal training is at all necessary it should wait till the pupil has reached a level of maturity which makes it possible for him to be motivated by the aim of the formal training. It follows that a formal training which aims at a transfer of the acquired skills to other subjects, or a formal training aiming at skills which the pupil will never master, must be considered a waste of time and have no place in the teaching of special schools. Further, it must be remembered that competition will serve as motivation only for the best pupils or the best group of pupils. The best motivation is successful work and the acceptance of this success by the surroundings.

\section{METHOD DETERMINED BY THE SUBJECT MATTER}

Even when perception is intact and the pupil is motivated for learning, he must take active part in the work in order to benefit from the instruction. There must be visual, auditory, and motor rapport between teacher and pupil, and this rapport must be carefully planned by the teacher before the lesson. The demand for personal activity necessitates special measures when individual instruction is employed. The pupils who are not under direct instruction from the teacher must be occupied with teamwork, or they must work individually with materials that can be handled by the pupil without constant instruction and control from the teacher.

As a consequence of this there must always be sufficient material in the class so that all pupils can be adequately occupied, and the material must aim at a definite learning goal. Materials which are employed out of custom because teacher or pupil like them must be avoided if they have no relation to the work in progress.

\section{HOME WORK}

Homework may be useful in the further teaching of subject matter that has already been learned at school, if the work is planned in such a way that the pupil can continue the work alone or with the help of his parents. In a school for mentally retarded children it will usually be best that this training take place at the school with the help and control of the teacher. This is the best way to avoid stress situations between the pupil and his home, the pupil and the school, or home and school.

Another consideration is the time spent by many pupils on the way to school and back home. It will be impossible for many of them to undertake further work.

Thus homework should not be a regular occurrence, but should be employed in special cases for particular reasons.

The best form for homework is the collection of materials and information that can be employed during the lessons. This will often serve as inspiration, especially in subjects concerning general knowledge. It can be performed without the help of the parents and without 
direct contact between teacher and home.

\section{ORGANIZATION OF THE EDUCATION}

The organization of groups and classes ought to be made on the basis of living age in consideration of the importance for each pupil to belong to a group of peers and to have a solid position in the group.

Children of the same age will often have common interests, and as the greater part of the education is usually administered as personal instruction or instruction of small groups, there will be no difficulty on account of the different intellectual standing of the pupils in a class. On the other hand, the distribution after living age must not be administered so strictly that there is no room for individual considerations. Strong sympathies or antipathies between two pupils or between a teacher and a pupil may be a good reason for placing a pupil in a class with older or younger pupils, and psychological or pedagogical reasons will also have to be taken into consideration.

At the end of the year some pupils will be moved to a higher class, but it must be remembered that this system may create a negative motivation towards the schoolwork with pupils who are not moved up, and that many of the pupils have been referred to the schools for mentally handicapped pupils on the basis of the experience that they could not meet the demands for removal in their old school. The greatest consideration, however, is the placement of the pupil in the class where he or she is best suited, but transfers must only take place after careful preparation of all parts involved (especially of the pupil himself). It is often a good idea to let a pupil start his removal to another class as a guest. Decisions of this sort are always a matter of the teachers' council.

The subject matter and the observations of the teacher must be carefully written down together with the progress, stagnation, or regression of the pupil, and all this must be evaluated by the teachers' council and, in special cases, by specialists. All observations must later be condensed into a description of the pupil and his possibilities when he is about to leave school. It is important that these final accounts are so realistic and purposeful that those who read them can understand the language employed by the school and get a clear picture of the school's evaluatign of the child's possibilities in life and work. Of course we whave not forgotten the fact that the pupil, in a new situation and among new people, may function in quite inother way than has been noticed by the school throug i several years.

During the les ons there must be recreational pauses with due consideration to the subject matter and the capability of each pupil, even when the pupils seem to enjoy the situation. The usual length of a lesson must not be surpassed ( 45 or 50 minutes) unless there are natural pauses for rest in the work itself, as will be the case in housework or dramatizing. The effect of the instruction is further dependent on the time of day; consequently the same subject matter must not always be placed at a time of day when the pupils are tired. For this reason it will seem natural to give longer breaks toward the end of day, with a corresponding reduction in the length of the lessons.

If pupils who are only ripe for a few lessons a day must stay at the school for longer hours, for reasons of transportation or other things of no educational importance, there must be possibilities for recreation (recreation class or the like).

\section{REGULATIONS}

It will not be necessary to give general regulations for the life in a special school. The regulations must depend on the number of pupils, special difficulties of the pupils, housing, and so on. It is generally agreed that the fewer rules the better, but on the other hand there must be certain house order to facilitate the work of the school in a reasonable way. It is a common experience that the more the pupils are allowed to take part in the elaboration and execution of the rules, the more smoothly we can expect the inner life of the school to flow. A democratic system of this sort is of great importance in the education of the pupils.

\section{SCHOOL AND HOME}

It has been stressed above that a good atmosphere between school and home is a necessary condition for the education of the special schools to have its full effect. This cannot be achieved in all cases, but it is important for the school to plan its collaboration with the home in such a way that no chance for a good result is missed. There are various forms of contact, and it must be remembered that the parents of a handicapped child have been exposed to so many visitš and interviews from public institutions that it may be difficult for them to understand that the school invites them to a collaboration. The rapport with the home must be naturally motivated in the way we work with the children, and to a certain extent we must let the parents choose whether the rapport shall take place in the parents' home, in the school or in the less personal form of class or school meetings.

If the parents visit the school without any previous arrangement, we must find a place where we can speak 
together without being disturbed, and on no account should this conversation be carried on in the presence of the class.

All forms of rapport with the parents must be part of the school's activity, and it will often be natural to activate the parents to take part in excursions, picnics, festivals, and the like. It is important for the parents to feel a close bond with the school, and understand that the service the special sohool can offer gives the best result if they take an active part in its life.

In every rapport with the parents the teacher must take care that the discussions of their children take place in an atmosphere of respect and friendliness, but they must also be realistic and not create hopes that have no roots in actual facts.

If the school arranges an exhibition of the pupils' work at parents' meetings or the like, these exhibitions must be organized in such a way that they show the work of the group or the class and not of each pupil. But of course the parents will always be welcome to attend the daily instruction and thus get an impression of their own child.

\section{OUTER FRAMEWORK FOR THE SCHOOLWORK}

With the great variety of instruction it is necessary that both teacher and pupil have a wide scope for their activity. As a consequence, the new special schools have been built after lines that give many possibilities for the rooms to be employed in different ways: the desks can be placed in various arrangements and the supplementary rooms can be employed for many sorts of work, including occupations which had not originally been thought of.

But there are also possibilities outside the classroom, e.g., swimming in the local swimming pool, games in. a public stadium, if the school has not got one of its own, visits to institutions and objects of interest in the surroundings, camp schools in other parts of Denmark and perhaps abroad, places which the pupils do not know beforehand, and so on. All this follows from the necessity of giving the pupils a concrete motivation for the education in order to enable them to lead a satisfying life afterwards.

\section{REMARKS CONCERNING THE CURRICULUM}

As will be seen, the curriculum mentions only the usual subjects, but of course this does not mean' that there is no place for special instruction, e.g., speech therapy, extra reading, choirs, excursions, and camp schools. The distributions of lessons for each subject is not exactly the same for all/schools, but the above curriculum must be considered as the standard we have been aiming at through our planning during the last years. It has been mentioned that transport might influence the number of lessons for some pupils. However, this is not often the case nowadays, because most schools have an effective bus service. In some schools there may be special considerations as to rooms and number of teachers, but this will never influence the principles of the plan. It is possible to carry through the curriculum whether a school works five or six days a week.

It has been maintained now and then that a division into different subjects as mentioned above is in contrast with the therapeutic aim of the school. From this report it will be understood that we try to solve this problem by means of collaboration between the various subjects, teamwork between the teachers, common lessons, modern methods of instruction, etc., so we feel convinced that it is possible to solve this part of our task as well within the given framework.

The conversation hour must be considered as an offer to the children to help them with their language and concept-formation. The subject of hygiene and body care is specially meant for the big girls to show them the importance of their outer appearance and general behavior.

The curriculum has been planned only up till the sixth form (including the preparatory classes), because this is the most common type of school. In the big schools it will be possible to introduce greater differentiation in the education and to introduce new subjects.

\section{QUALIFICATIONS OF THE TEACHER}

There have been no investigations made as to the character of the teachers who have chosen to work in schools for the mentally handicapped, neither as to their social background or their attitude to the work with the mentally defective, nor as to their general attitude about the ideas of society. Until such an investigation has been undertaken, we must be careful not to jump to the conclusion that our teachers are more idealistic than others or that they have a broader human margin (for instance as to patience). A question of this sort may seem irrelevant for an educational guidebook, but if a book of this sort is to be of any help to the teachers who are supposed to realize its ideas, it muist be written in a spirit and a language that can be understood and accepted by the teachers. Further, the trend of their work will be influenced both by their own supplementary education and by the attitude of people in general towards their work with mentally handicapped.

An education on the lines sketched above makes heavy demands on the teacher. At the end of training school 
the qualifications of the teachers are widely different, and teachers with extra training in special pedagogics are far too few to cover the demand of the special schools. It is therefore quite natural that a teacher on his nomination is submitted to the obligation of a supplementary education of one year. But even the capacity of these supplementary courses is not great enough by far to cover the demands of both older teachers who want to have their knowledge brought up to date and new teachers applying for appointment. In order to keep up with the new ideas in psychology and pedagogics the teachers must undertake a good deal of private studying and take part in shorter courses and meetings, some obligatory, others voluntary. It isfextremely important to intensify this supplementary education of the teachers. Otherswise all great efforts would have only superficial value and solve no real problems.

\section{MEETINGS AND CONFERENCES}

There must be frequent meetings and conferences among the teachers, and the object of each meeting must be clearly defined beforehand. We can distinguish between three different sorts of teachers' meetings, apart from the meetings of the teachers' council, which has a special function.

a. Meetings concerning the pupils, with the object of discussing the problems of one or more pupils and trying to find an acceptable solution.

b. Meetings concerning staff and work, discussing among other things the coordination of various subjects, general pedagogical problems (without relation to special pupils), transport, collaboration with parents, etc.

c. Announcements, where the leader of the school calls a conference to inform the staff, e.g., about new regulations, announcements from the centers, new pupils, holidays, or the like.

In planning and executing his instruction, it is not enough for the teacher to know the child as a pupil on whom there is a long case history. In order to know the pupil thoroughly and to understand his reactions in various situations at school the teacher must know his home and surroundings (friends, spare time occupation, general tolerance, social position, and so on). To acquire this knowledge the teacher must visit the pupil's home and always be acquainted with changes outside the school which might motivate a new approach towards the child. (See paragraph above on organization).

If the teacher employs tests of any sort, he must know exactly which conclusions to draw from the answers and what limitations must be taken into consideration. The original diagnosis of a pupil must be followed up through distinctive tests.

All changes in a pupil's standard must be entered into the case history. During the lessons the teacher ought to write down details that may later prove important in the description of the pupil, otherwise it will be impossible to retain the fleeting impressions. Without periodical notes, entries into the case history will often become a description of the present standard of each pupil, and not an evaluation based on continuous observations. It is important to note that the case history, which must always follow the child and be filed at the school, is one of the most important tools in planning an all-around treatment. However, the case history will only be of help if it is always up to date and if all information is available to the staff (which of course must use great discretion).

\section{A TEAM APPROACH TO MENTAL HEALTH IN A RURAL COMMUNITY SCHOOL}

\section{By Elizabeth C. Thomas and Raymond L. Feltner ${ }^{1}$}

Morse (1966) emphasized that no public school program can be thought of apart from provisions the community makes for disturbed children. This statement is particularly provocative when considered in light of existing conditions in isolated rural sections of our nation, where there is access to few mental health facilities and where the community makes no provisions for disturbed children. In the rural setting the school becomes the primary avenue of social development and interaction for children who are otherwise limited almost exclusively to contact with members of their immediate family. If the family has problems, there are fewer escapes for the rural child. Such children suffer the effects of family

1. Elizabeth C. Thomas, Ph.D. is a member of the faculty of the Special Education Department of the University of Virginia. Raymond L. Feltner is Director of Special Services for the Hutchinson, Kansas Public Schools. This project was supported by the Division of Special Education of the Iowa State Department of Public Instruction. 
tensions and experience emotional conflicts which, in turn, affect school adjustment. Schools must find a way to help these children.

\section{PROGRAM OBJECTIVES}

This team approach, incorporating a modification of Morse's conception of crisis intervention (1966), was conceptualized as a program for improving mental health in the rural school environment. A program of this nature does not label or segregate maladjusted children, but rather provides an opportunity for the child to work out solutions to his problems within the regular classroom environment. The child's most effective realization must come through both school and home environments, and consequently team members were concerned with implementation in both settings. Four general objectives served as a framework for the formulation of individual objectives for each program child: (1) To promote academic functioning of the child commensurate with his mental age; (2) To aid the child in developing social skills with peers and adults and to help him function more effectively in group situations; (3) To aid the child in emotional growth, emphasizing development of ade(1) quate self-concept and improved attitudes toward others; and (4) to involve the parent(s) constructively in their child's program. A fifth and equally important objective was that of provision of inservice teacher training, focusing upon hygienic techniques of behavior management.

\section{PROGRAM}

The program was initially designed for a two-year period with the intention of developing it to the point of independent operation by local school personnel. Two years was also considered the minimum length of time necessary for effective inservice teacher training. While the program was to have been supported by the state for two years, financial considerations other than those directly connected with the program led the community school board to discontinue its support after its first year of operation.

\section{SELECTION OF PUPILS}

In a small rural elementary school of approximately 600 children, staff and classroom teachers were fully aware of those children who were undergoing adjustment difficulties, a situation which provided fairly immediately leverage for working with both child and parent(s). In the spring preceding the initial project year, students were referred by classroom teachers on the basis of poor academic performance and behavioral adjustment difficulties. A battery of individual intelligence and group achievement tests was administered by the school phychologist, and eleven children were screened for the program. Five were selected by the principal, school psychologist, and teachers as being in most urgent need of help, and are hereafter referred to as the "special program" group for the first year of the project. The remaining six children formed the intended special program group for the second year of the project, and were to be added at that time to those already included. Hereafter they will be referred to as the "no special program" group.

In order to gain parental support, at this point the principal held a conference with the child and parent(s) during which he explained the nature of the program and inquired as to their interest in participating. These parents who were also experiencing difficulties with their children at home were enthusiastically supportive.

\section{INITIAL PSYCHIATRIC INTERVIEW}

An additional modification of the crisis teacher plan is the use of an initial psychiatric evaluation, a requirement of the state which funded the project. The crisis teacher plan, by contrast, directs that the school request further expertise only after it has exhausted its own resources (Morse, 1966). However, in the supportive teacher program, both children and mothers consented to individual psychiatric interviews. While these evaluations were not directly helpful, they were confirmatory of the serious illness of the children who were participating in the program.

As a group, these children had severe motivational problems. They were immersed in conflict situations in the home which drained much of their energy. Some had given up completely ip the school situation, viewing themselves as persons who could not learn. In academic achievement they were functioning from one to two years lower than expected. In all cases a considerable amount of ego support was a basic need.

Following the initial psychiatric assessment, the social worker completed a history on the home life of each child. At this point the team was ready to formulate individual programs for the five children.

\section{THE TEAM AND ITS FUNCTION}

Because of the difficulty involved in attracting qualified specialists to the rural area, availability of personnel was somewhat limited. Those selected met at least the broad minimum requirements of possessing some training in mental hygiene. The team yas composed of the school principal, supportive teacher, school psychologist, school social worker, special education director, and 
a psychoeducational consultant. The principal, social worker, and school psychologist held master"s degrees; the special education director held a master's degree in psychology and advanced graduate training with certification in special education administration; and the psychoeducational consultant held a Ph.D in education and psychology. While the latter was associated with a nearby university, the principal and supportive teacher were employed by the community school district; and the social worker, a school psychologist, and special education director were employed by a four-county special education program. The social worker, school psychologist, and psychoeducational consultant had had prior experience in psychiatric institutions and each brought much of his clinical experience to the program. The team held staffings twice monthly, made all major decisions, formulated in-school and out-of-school programs for each child, and designated individual team members, to implement specific portions of each program.

As a longtime resident of the local community, the elementary shool principal served as a natural center for communication, and was continuously available to receive and transmit information. Other team members, excluding the supportive teacher, were available on specified days each week. The school social worker made monthly home visits and held weekly counseling sessions with two of the subjects. The principal, school psychologist, and psychoeducational consultant administered psychological and academic 'testing. Working through the regular classroom teachers and supportive teacher, the psychoeducational consultant was also closely involved in supervision of the academic and psychosocial program for each child.

The role of the supportive teacher was modified from that of the crisis teacher and was in harmony with his experience and professional training in elementary education. His role, therefore did not include life-space interviewing (Morse, 1963), a guidance function (Morse, 1965), or a part in the insezyice training program (Morse, 1966). He maintained a tutoring schedule with all subjects and aided in social activities, doing much that the regular teacher lacked time for implementing. The psychoeducational consultant directed the supportive teacher in all his activities and held weekly conferences with him and with the classroom teachers.

\section{COMMUNITY RESOURCES}

The crisis teacher plan relies upon community agencies for their cooperation, and they offer mutual reinforcement in realizing programs for the disturbed child. As applied to the rural setting, a survey of community re- sources identified a minister, a Girl Scout leader, and a physician who could provide assistance. These resource persons were contacted by the team members, were made aware of the difficulties each child experiences, and were able to aid in broadening social contacts and improving peer relationship outside the immediate school situation.

\section{CLINICAL APPROACH}

The clinical approach was essentially a child study method. The initial phase involved the psychoeducational consultant working with the class room teacher. Each special program child was observed by all team members in both academic and social situations within the school setting. These observations were followed by a conference with the teacher during which recommendations were made as to how the regular classroom teachers and supporting teacher could help each child.

At this point a staffing was held and individual programs formulated. Data from the psychologist, social worker, and psychoeducational consultant plus teacher conferences were available to the team. In cases where medication was prescribed, the school nurse participated in staffings. Staffings were held twice monthly thereafter to review progress and alter the program where indicated. Reports from the regular teachers, supportive teacher, and social worker provided information regarding such aspects as academic work, social activities, responsible home training, and provision of appropriate age peers for after-school activities. For those program children who were to be promoted to junior high school, a conference was held with the receiving principal and school counselor to facilitate improvement in the new school setting.

Another aspect of the clinical approach, in lieu of lifespace interviewing, was the social worker's interaction with the two older girls, with whom she held weekly thirty-minute sessions. The conversation, based on reality siturions, progressed in a nonthreatening, nonjudgmental manner, allowing the pupil to express her own perception and biases. While depth and spread of behavior were of interest to the social worker, she did not probe or confront. Sometimes problem resolutions resulted; at other times there was temporary cathartic relief.

The supportive teacher functioned much as does the resource room teacher, providing academic tutoring in daily twenty-minute sessions for those program children below graele four, and daily forty-five minute sessions for those in grades four through six. He also aided the children's social development and peer interaction through use of the "game corner" of his office. For ex- 
ample, he began by playing games with the child alone, then invited one or more children to participate in games with the program child, finally graduating to playground activity in which the program child could function more süccessfully with larger groups.

\section{INSERVICE TRAINING}

The major modification relative to inservice training was one of tempo. The team permitted the involvement of classroom teachers to grow out of their own needs and interests rather than requesting immediate full participation. Four phases, each of which indicates a deeper level of involvement by the teachers, can best describe this process. Phase I was the teacher's recommendation of children for the program. Phase II consisted of a series of individual conferences with the psychoeducational consultant and supportive teacher. Deeper involvement resulted in Phase III when teachers joined team staffings for initial formulation of a child's program and made subsequent progress reports. Total teacher involvement resulted after midyear when, in Phase IV, the teachers of siblings of conferenced children requested conference participation. Through increased understanding of the child's needs and immediate application of suggested coping techniques, participating teachers altered their general perceptions and attitudes toward children and their behavior.

\section{PROGRAM ASSESSMENT}

Children of both groups were given the following preand posttests: California Test of Personality, Metropolitan Achievement Test, and a sociometric test consisting either of six or ten items, depending upon the age group to which it was administered. It was given in all classrooms having one or more project children. The items were similar to those of Bower and Lambert (1962). The total pretest battery was administered in November and the posttest battery in May, providing a six-month interim for the first annual assessment.

\section{APPRAISAL}

No effort was made to produce an experimental study, but rather to provide an effective program to meet teacher and student needs. The assessment instruments employed tended to support some of the team's decisions and to further describe the program.

Table I indicates smaller gains measured by the Metropolitan Achievement Test' in the "special program" children than in the "no special program" children. If a slower rate of achievement of one group of children compared with another group of equivalent intelligence (the mean and range of S-B intelligence quotients were nearly identical) indicates more serious school problems, then the principal did, indeed, select those most urgently in need of help. Initially the team hypothesized that intervention which interrupted the downward trend of specific scores in academic areas would be considered successful progress in the first year. Children I through IV met this criterion of success. Child V, making progress in only three areas, is the one exception. Special tutoring may account for improvement in arithmetic at a greater rate than expected. Since children I and II were receiving tranquilizers known to affect cognitive functioning, the results of their progress are tentative upon their functioning after tranquilizers are discontinued. The "no special program" group appears to have made similar progress, with children $\mathrm{X}$ and $\mathrm{XI}$ making

$$
\begin{gathered}
\text { TABLE } 1 \\
\text { DIFFERENTIAL GAIN SCORES } \\
\text { IN ACHIEVEMENT } \\
\text { Grade Reading Arith Lang. Social Science } \\
\text { Studies }
\end{gathered}
$$

Special

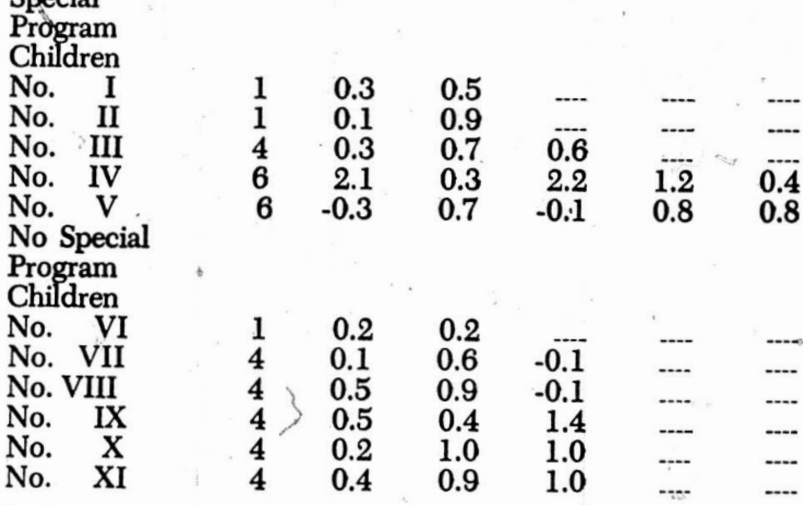

better than average progress. Knowledge the teachers acquired in working with the special program children was perhaps being applied to others they had originally referred. Since inservice teacher training was a major part of this program, no effort was made to interfere with this transfer of learning. 1

The California Test of Personality yielded pre- and posttest scores at or below the fiftieth percentile in most cases (Table 2). Higher scores for the first grade children may be a function of the questionable validity for younger children. Discrepancies between pretest and posttest scores are interesting. In terms of observable behavior and attitudes the "special program" children improved, yet they marked themselves lower on the posttest. This may be a function of increased insight in the case of children II, III, and IV. It was doubtful to the team that child $\mathrm{V}$ gained any insight into his difficulties, 
TABLE 2

\section{PERCENTILE SCORES ON CALIFORNIA TEST OF PERSONALITY}

Special

Pretest

Posttest

Difference

Program

No. I

No. II

No. III

No. IV

No. $V$

No Special

Program

Children

No. VI

No. VII

i No. VIII

No. IX

No. $\mathrm{X}$

No. XI

60
50
10
10
1

$-20$

$-10$

$-40$
20

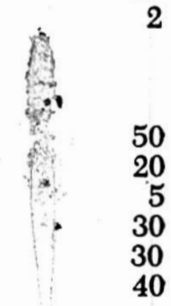

and differences in the pre- and posttest scores seem to substantiate these impressions. The low percentile scores on the California Personality Test coincide generally with the high frequencies of negative nominations on the sociometric questionnaire (Table 3). Either these children were seen by their peers as negative, or they had little visibility in the classroom social milieu. While observable change in child IV was noted by team members, interpretation based on pretest and posttest sociometric questionnaires, which came from different peer groups, is not reliable. Child V's withdrawal, inept coping techniques, and hostility are reflected in his high negative.

\section{TABLE 3 \\ FREQUENCY OF POSITIVE AND NEGATIVE NOMINATIONS ON SOCIOMETRIC QUESTIONNAIRE}

\begin{tabular}{llrrrrr} 
& \multicolumn{3}{c}{$\begin{array}{c}\text { Positive } \\
\text { Special }\end{array}$} & Pretest Posttest & D & \multicolumn{2}{c}{$\begin{array}{c}\text { Negative } \\
\text { Pretest Posttest }\end{array}$} & D \\
$\begin{array}{l}\text { Program } \\
\text { Children }\end{array}$ & & & & & & \\
No. 1 & 1 & 1 & 0 & 1 & 6 & 5 \\
No. II & 1 & 0 & -1 & 5 & 3 & -2 \\
No. III & 2 & 1 & -1 & 2 & 0 & -2 \\
No. IV & 1 & 0 & -1 & 16 & 3 & -13 \\
No. V & 0 & 1 & 1 & 12 & 26 & 14 \\
No Special & & & & & & \\
Program & & & & & & \\
Children & & & & & & \\
No. VI & 0 & 0 & 0 & 16 & 28 & 12 \\
No. VII & 0 & 0 & 0 & 17 & 8 & -9 \\
No. VII & 3 & 0 & -3 & 24 & 21 & -3 \\
No. IX & 0 & 1 & 1 & 0 & 0 & 0 \\
No. X & 8 & 7 & -1 & 0 & 1 & 1 \\
No. XI & 1 & 1 & 0 & 4 & 7 & 3
\end{tabular}

\section{CONCLUDING STATEMENTS}

The clinically oriented team approach, emphasizing cooperation without any hierarchy of power among members, demonstrated to teachers and school officials how they could study and work constructively with the children's problems. The teachers, who possessed equal status with other team members, were made more aware of the importance of their own role and responsibilities.

It is most likely that the pathology of the "special program" children remained unaltered. However, their perception of school and their attitudes towards themselves and their peers improved. The school social worker's interaction with the parents appears of much greater significance. She had some impact on changing the family life and she did convince the parents that their child needed professional help, something beyond what they or the school could give. This may, in itself, be the major lasting accomplishment of the program in this rural community school.

\section{REFERENCES}

Bower, Eli M. and Lambert, Nadine. A Process for In-School Screening of Children with Emotional Handicaps. Princeton, N. J.: Educational Testing Service, 1962.

Morse, William C. Working paper: Training Teachers in LifeSpace Interviewing. American Journal of Orthopsychiatry, 1963, $33(4), 727-730$. Emotionally Disturbed Children. In Knoblock, P.

(Ed.), Educational Programming for Emotionally Disturbed Children: The Decade Ahead. Syracuse University Press, $1965,29-41$.

In Knoblock, P. (Ed.), Intervention Approaches in Educating Emotionally Disturbed Children. Syracuse University Press, 1966, 113-128.

\section{WASHINGTON REPORT}

The National Special Education Information Center (SEIC) was scheduled to become operational on April 1. The Center's information retrieval system stores facts about special education programs in 20,000 public school systems and 4,000 residential facilities.

SEIC is part of the program for Recruitment of Personnel and Information on Education of the Handicapped. Its two-part purpose is to improve methods of attracting personnel to careers in the field of special education and to improve the dissemination of information concerning educational opportunities for the handicapped.

The Surveys and Research Corporation was given a 
grant to develop the National Special Education Information Center. A parallel contract was entered into with the Robert P. Mullen Company to develop the public relations aspect of the recruitment program.

Recruitment advertising developed by the Mullen Company will be carried on television, radio and in all major community newspapers. It will appear on billboards and posters and will be presented to all professional associations concerned with handicapped children.

Each ad will encourage students or those thinking of a change in vocation to contact Closer Look, Box 1492, Washington, D. C. for more information about career opportunities in special education.

A television advertisement narrated by Anne Bancroft is directed at parents of the handicapped. It will name characteristics which may indicate a handicapping condition and will encourage parents who suspect their child may be handicapped to contact Closer Look.

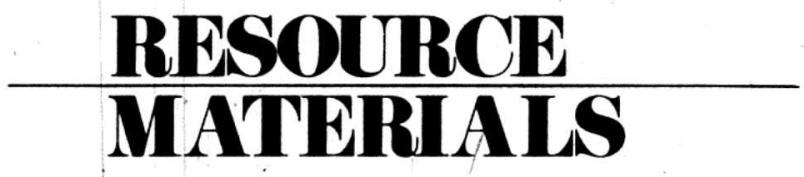

By Reuben Altman and Linda Smith

\section{BOY SCOUTS OF AMERICA}

Recognizing that individual differences characterize children throughout their developmental years, the Boy Scouts of America is dedicated to the conviction that Scouting is for all boys. This organization, in coopera tion with the National Association for Retarded Children, has adapted its program for the mentally retarded by modifying the traditional eligibility requirements and materials. Publications are available to assist local scouting units in integrating the handicapped into their programs. Modifications for all handicapped groups are in keeping with the basic tents underlying the national scouting movement. Scouting capitalizes on the natural interests of boys to promote character building, citizenship training, and physical fitness. Scouting contributes a sense of belonging; accomplishment, and personal worth to the handicapped as well as an opportunity to associate with the non-handicapped.

Appropriate literature and resource materials facilitating the implementation of programs for the emotionally

1. Reuben Altman is Consultant and Linda Smith is Curriculum Specialist, Special Education Instructional Materials Center, The University of Texas at Austin. disturbed, orthopedically handicapped, and the deaf are also provided. In addition, scouting handbooks, pamphlets, and magazines are distributed in Braille, largeprint, and on records and tapes for the blind and partially sighted. Further information may be obtained from your local Boy Scout Service Center or by writing: School Relationships Service; Boy. Scouts of America; New Brunswick, New Jersey 08903.

\section{THE NATIONAL ASSOCIATION FOR MUSIC THERAPY}

The National Association for Music Therapy was founded in 1950 to stimulate the development of the art of music to accomplish therapeutic aims. Music activities have been found to be effective in modifying the behavior of handicapped children partially in providing an avenue for the expression of otherwise inhibited emotions. Inclusion of music therapy techniques in special education programs has accelerated beyond the emotionally disturbed to encompass the mentally retarded, the cerebral palsied, the blind, and the multiply handicapped. The Association will provide interested individuals with a list of accredited institutions offering training in this field as well as brochures providing other information pertinent to. professional requirements. An Associate membership status is available for $\$ 5.00$ which includes subscription to the quarterly publication, The Journal of Music Therapy. For fürther information or membership applications, write: National Association for Music Therapy; P. O. Box 610; Lawrence, Kansas 66044.

is

ISSUES

E TRENDS

As one reviews the literature on exceptional children, it becomes apparent that there is a minimum of input on international activities. Articles by Americans do appear. For the most part, these are descriptive articles resulting from visitations. The article from Denmark appearing in this issue is the first of what hopefully will become a series of articles on international concerns in the education of the mentally retarded and emotionally disturbed.

An attempt is being made to identify programs and projects in various countries which would be of interest to special educators in the United States. Persons aware of such programs are encouraged to forward suggestions to the publisher. 